\title{
O USO DOS JOGOS COOPERATIVOS COMO ESTRATÉGIA PEDAGÓGICA NA INCLUSÃO DE ALUNOS COM DEFICIÊNCIA INTELECTUAL NAS AULAS DE EDUCAÇÃO FÍSICA
}

\author{
THE USE OF COOPERATIVE GAMES AS A PEDAGOGICAL STRATEGY IN THE \\ INCLUSION OF STUDENTS WITH INTELLECTUAL DISABILITIES IN PHYSICAL \\ EDUCATION CLASSES
}

\section{EL USO DE JUEGOS COOPERATIVOS COMO ESTRATEGIA PEDAGÓGICA EN LA INCLUSIÓN DE ESTUDIANTES CON DISCAPACIDAD INTELECTUAL EN CLASES DE EDUCACIÓN FÍSICA}

\section{Resumo}

O trabalho busca discutir como o professor de Educação Física poderá melhor incluir estudantes com deficiência intelectual a partir da utilização de Jogos Cooperativos. O problema desta investigação apresenta-se: como a utilização dos Jogos Cooperativos contribui para inclusão de alunos com deficiência intelectual nas aulas de Educação Física em uma Escola Municipal de Salvador-BA? No objetivo geral, buscou-se compreender como os Jogos Cooperativos contribuem para inclusão de alunos com deficiência intelectual nas aulas de Educação Física em uma Escola Municipal de Salvador-BA. A metodologia deste trabalho pauta-se na pesquisa-ação, tendo como instrumento de pesquisa a observação sistemática, a entrevista semiestruturada, o diário de campo, jogos e o registro fotográfico para uma turma de $4^{\circ}$ ano do Ensino Fundamental em uma escola pública municipal de Salvador. Como aporte teórico, recorreu-se aos estudos de Brotto (2013), Correia (2006) e Soler (2005) nas discussões sobre os Jogos Cooperativos, e para a Educação Especial e Inclusiva foram selecionadas artigos científicos, dissertações, teses e dispositivos legais. Resultado final tem-se que os Jogos Cooperativos contribuem para inclusão dos alunos com deficiência intelectual nas aulas de Educação Física, pois estimula a participação de todos, contribuindo no desenvolvimento de atitudes inclusivas como o respeito, a solidariedade e o diálogo.

Palavras-Chave: Jogos Cooperativos; Inclusão; Educação Física.

\section{Abstract}

The work seeks to discuss how the Physical Education teacher can better include students with intellectual disabilities through the use of Cooperative Games. The problem of this investigation is presented: how does the use of Cooperative Games contribute to the inclusion

\footnotetext{
${ }^{1}$ Especialista em Psicopedagogia Clínica e Institucional pela Faculdade Adventista da Bahia. Docente na Secretaria Municipal de Educação de Salvador.

E-mail: rodrigosantosvita@gmail.com

ORCID: http://orcid.org/0000-0001-9282-5912

2 Doutora em Educação pela Universidade Federal da Bahia. Docente no Programa de Pós-

Graduação em Educação de Jovens e Adultos da Universidade do Estado da Bahia.

E-mail: patricia@inclusaodahora.com.br

ORCID: https://orcid.org/0000-0001-8041-1827
} 
of students with intellectual disabilities in Physical Education classes at a Municipal School in Salvador-BA? In the general objective, we sought to understand how the Cooperative Games contribute to the inclusion of students with intellectual disabilities in Physical Education classes at a Municipal School in Salvador-BA. The methodology of this work is based on action research, with systematic observation, semi-structured interview, field diary, games and photographic record as a research tool for a 4th grade elementary school class in a public municipal school in São Paulo. Savior. As a theoretical contribution, the studies of Brotto (2013), Correia (2006) and Soler (2005) were used in discussions on Cooperative Games, and for Special and Inclusive Education, scientific articles, dissertations, theses and legal devices were selected. The final result is that the Cooperative Games contribute to the inclusion of students with intellectual disabilities in Physical Education classes, as it encourages the participation of all, contributing to the development of inclusive attitudes such as respect, solidarity and dialogue.

Keywords: Cooperative Games; Inclusion; Physical Education.

\section{Resumen}

El trabajo busca discutir cómo el docente de Educación Física puede incluir mejor a los estudiantes con discapacidad intelectual mediante el uso de Juegos Cooperativos. El problema de esta investigación es: ¿cómo contribuye el uso de Juegos Cooperativos a la inclusión de estudiantes con discapacidad intelectual en las clases de Educación Física de una Escuela Municipal de Salvador-BA? En el objetivo general, se buscó comprender cómo los Juegos Cooperativos contribuyen a la inclusión de estudiantes con discapacidad intelectual en las clases de Educación Física de una Escuela Municipal de Salvador-BA. La metodología de este trabajo se basa en la investigación-acción, utilizando la observación sistemática, la entrevista semiestructurada, el diario de campo, los juegos y el registro fotográfico como herramienta de investigación para una clase de $4^{\circ}$ de primaria de una escuela pública municipal de São Paulo. Salvador. Como aporte teórico, se utilizaron los estudios de Brotto (2013), Correia (2006) y Soler (2005) en discusiones sobre Juegos Cooperativos, y para Educación Especial e Inclusiva, se seleccionaron artículos científicos, disertaciones, tesis y dispositivos legales. El resultado final es que los Juegos Cooperativos contribuyen a la inclusión de los alumnos con discapacidad intelectual en las clases de Educación Física, ya que fomenta la participación de todos, contribuyendo al desarrollo de actitudes inclusivas como el respeto, la solidaridad y el diálogo.

Palabras clave: Juegos cooperativos; Inclusión; Educación Física.

\section{Introdução}

Com o advento das propostas da educação inclusiva, as escolas passaram a ter que se reestruturar em sua lógica de funcionamento para tornar-se um local mais acolhedor e acessível. Antes, o direito de frequentar as escolas era um privilégio apenas daqueles que se enquadravam nos padrões de normalidade vigente na sociedade. Visando eliminar essas barreiras segregacionistas, grupos sociais de apoio aos direitos humanos, bem como instituições de defesa das pessoas com deficiência, se mobilizaram em prol de estabelecer políticas públicas mais 
igualitárias. Esse movimento inaugurou um novo paradigma educacional; isto é, a educação inclusiva.

O movimento de educação inclusiva tem como propósito a construção de uma escola democrática, na qual as necessidades específicas de cada aluno sejam contempladas nos planejamentos pedagógicos, e a diversidade seja reconhecida e valorizada como uma característica intrínseca de cada sujeito. Consequentemente, a partir desse movimento, observa-se, na contemporaneidade, um aumento exponencial nas matriculas dos alunos com deficiência e transtornos globais do desenvolvimento no ensino regular. Neste contingente populacional, encontram-se àqueles com deficiência intelectual.

A American Association On Mental Retardation (Associação Americana de Retardo Mental) descreve que a deficiência intelectual se caracteriza por limitações significativas nas funções intelectuais e no comportamento adaptativo que compreende diversas habilidades sociais e funcionais (AMERICAN ASSOCIATION ON MENTAL RETARDATION, 2006). As pessoas com deficiência intelectual não apresentam apenas um padrão comportamental, seus valores morais e a forma como veem o mudo são diferentes, conforme o contexto social no qual estão inseridos e os estímulos que recebem, e todos esses aspectos interferem no seu desenvolvimento e na sua forma de aprender (MENDONÇA; FLAITT, 2013).

A Educação Física é um componente curricular que tematiza as práticas corporais como os esportes, as danças, as luras, as brincadeiras e os jogos (BRASIL, 2017). contribuir significativamente no desenvolvimento integral dos indivíduos. Por meio da vivência destas práticas corporais os indivíduos podem desenvolver-se nos aspectos sociais, cognitivos afetivos e psicomotores.

No entanto, é importante evidenciar que pesquisas vêm sendo desenvolvidas atestando que as pessoas com deficiência ainda sofrem com a segregação e a discriminação, sobretudo, quando sua deficiência compromete o desenvolvimento das atividades (DUBOC, 2019). Além disso, quando nas aulas há uma predominância de atividades competitivas, há uma tendência maior dos alunos com deficiência sofrerem com a segregação e o preconceito (DUBOC, 2019). Resultados semelhantes são encontrados nos estudos de Silveira e Seron (2020), bem como os de Furtado et al (2019). 
A Educação Física Escolar tem em sua trajetória histórica forte influência dos esportes de rendimento, e um dos aspectos marcantes desta prática corporal é a competição. Nas atividades onde se predomina a competição, um grupo alcançará seus objetivos se e somente se o grupo adversário não alcançar o seu. A Educação Física, portanto, no momento em que incorpora como conteúdo de ensino e aprendizagem o esporte, incorpora também para si os aspectos competitivos desta prática, e os resultados de uma valorização excessiva da competição nas práticas de ensino da Educação Física pode ser evidenciada nas aulas em comportamentos antissociais de negação do outro e de segregação.

Contrariando essa lógica, os Jogos Cooperativos emergem como um espectro de práticas corporais que fomentam valores como a solidariedade, o companheirismo a aceitação do outro e o diálogo (BROTTO, 2013). Surgiram para surgiram para contrapor a excessiva valorização dada ao individualismo e à competição exacerbada existente na sociedade moderna. No campo acadêmico-cientifico, as pesquisas envolvendo os Jogos Cooperativos ganha evidência no campo da Educação Física (ABRAHÃO, 2004; FERRI, 2018; BROTTO, 2013; MOREIRA, 2017; FIDALGO, 2015 e MONTEIRO, 2006).

Diante do que foi exposto; isto é, a exclusão enfrentada pelos alunos com deficiência nas aulas de Educação Física, bem como a potencialidade dos Jogos Cooperativos como uma prática corporal inclusiva, surge o problema da presente pesquisa: como a utilização dos Jogos Cooperativos contribui para inclusão de alunos com deficiência intelectual nas aulas de Educação Física em uma Escola Municipal de Salvador-BA? Diante do problema em questão, buscou-se neste trabalho compreender como os Jogos Cooperativos contribuem para inclusão de alunos com deficiência nas aulas de Educação Física em uma Escola Municipal de Salvador-BA.

\section{Metodologia}

Para a construção deste trabalho, optou-se por uma abordagem qualitativa descritiva. Como estratégia metodológica, decidiu-se pela pesquisa-ação, sobretudo por acreditar que uma pesquisa não deve limitar-se a investigar apenas aspectos acadêmicos e burocráticos, como ocorre na maioria das pesquisas 
convencionais (THIOLLENT, 2011). Para coleta de dados, foram utilizados os seguintes instrumentos: a observação sistemática, a entrevista semiestruturada, o diário de campo, jogos e o registro fotográfico. Como aporte teórico na abordagem dos Jogos Cooperativos, foram utilizados em especial os estudos de Brotto (2013), Correia (2006) e Soler (2005). No tocante a educação especial inclusiva, tomamos como referência, além dos documentos oficiais publicados em território nacional e internacional, artigos, dissertações e teses.

O lócus escolhido para pesquisa foi uma Escola Pública Municipal de Salvador. O critério de escolha da instituição escolar como campo de pesquisa se deu pelo fato de um dos pesquisadores exercerem atividade profissional neste local como professor de Educação Física nas séries iniciais do Ensino Fundamental. Sobre os sujeitos que participaram da pesquisa, a amostra foi composta de um grupo de 20 crianças de uma turma do $4^{\circ}$ ano do Ensino Fundamental de ambos os sexos na faixa etária entre 8 a 10 anos. A escolha da turma foi intencional, e obedeceu ao critério da presença de crianças com deficiência intelectual em contexto de inclusão. Thiollent (2011, p.71) descreve o que ele denomina de "amostras intencionais" como "[...] um pequeno número de pessoas que são escolhidas intencionalmente em função da relevância que elas apresentam em relação a um determinado assunto". As outras turmas não foram consideradas na pesquisa porque não possuíam alunos diagnosticados com deficiência matriculados. Para participar da pesquisa, os responsáveis legais das crianças assinaram um Termo de Consentimento Livre e Esclarecido.

A pesquisa-ação se desenvolveu conforme a proposta de Thiollent (2013), dividida em três fases: 1) fase exploratória; 2) elaboração do tema e problema da pesquisa; e por último 3) elaboração e aplicação do plano de ação. A fase exploratória consistiu basicamente na identificação da situação-problema com suas variáveis, bem como o estudo prospectivo da viabilidade de uma intervenção por meio da pesquisaação. Em linhas gerais, nessa fase, verificou-se com a responsável legal da instituição escolar - lócus da pesquisa - a viabilidade de realização da pesquisa. Feito esse estudo, foi assinado por ela um termo de autorização garantindo as condições para realização da pesquisa. 
Figura 1 - Caminho metodológico da pesquisa

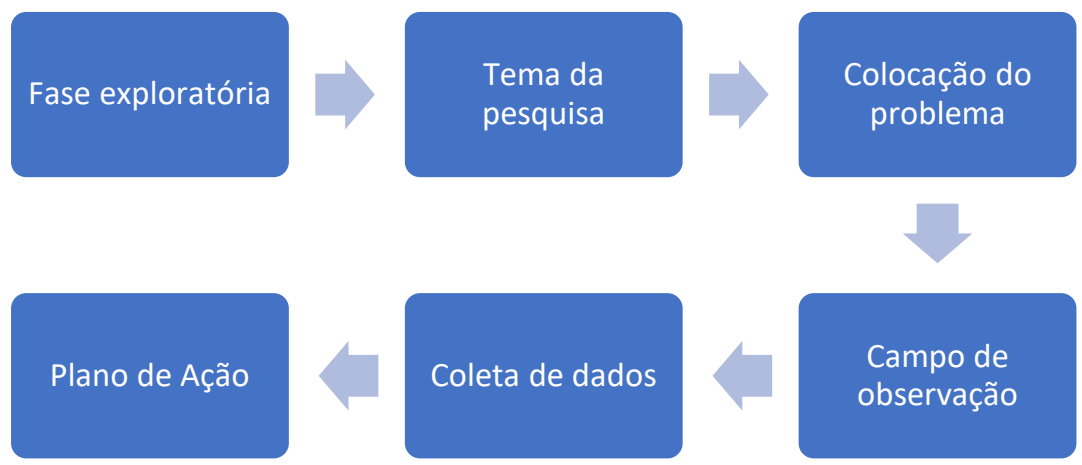

Fonte: Imagem feita com base em Thiollent (2011)

A segunda fase consistiu na definição do problema da pesquisa, que por sua vez, foi enquadrado em um marco teórico. Nesta mesma fase, após a definição do problema de pesquisa, foi solicitado aos responsáveis dos alunos que assinassem um Termo de Livre Consentimento e Esclarecimento. Dos 30 alunos contatados para participar da pesquisa, apenas 20 foram autorizados a participar. Os outros participaram da intervenção, mas não foram considerados na análise dos resultados. Com vistas a preservar sua identidade, seus nomes foram alteramos por nomes fictícios nas discussões.

Na última fase, foi elaborado e aplicado um plano de ação com viés de caráter educativo. Este plano teve como base um programa com Jogos Cooperativos vivenciados por uma turma do $4^{\circ}$ ano do Ensino Fundamental matriculados em uma escola pública municipal de Salvador. Dentre estes 20 alunos, dois deles são diagnosticados com Deficiência Intelectual.

A intervenção, que teve como tema central a inclusão por meio dos Jogos Cooperativos, ocorreu em quatro encontros de 50 minutos. Em cada um desse encontro, os alunos vivenciaram dois jogos eminentemente cooperativos, no qual foi possível verificar a forma como eles interagiam entre si e com os jogos. Os jogos foram escolhidos de acordo com o espaço e os recursos disponíveis na escola. No Quadro 1, são descritos o nome, os recursos, a ordem e a descrição os jogos utilizados. 
Quadro 1 - Descrição dos jogos cooperativos utilizados nas intervenções

\begin{tabular}{|c|c|c|c|}
\hline JOGO & RECURSOS & ORDEM & DESCRIÇÃO \\
\hline $\begin{array}{l}\text { Dança das } \\
\text { cadeiras } \\
\text { cooperativas }\end{array}$ & $\begin{array}{l}\text { Cadeiras e } \\
\text { aparelho de } \\
\text { som }\end{array}$ & $\begin{array}{l}1^{1 \text { a Aula }} \\
\text { (Primeiro } \\
\text { encontro) }\end{array}$ & $\begin{array}{l}\text { As cadeiras são dispostas em círculo, com os } \\
\text { acentos voltados para fora e com uma a menos do } \\
\text { que o número e participantes. Os participantes } \\
\text { posicionam-se, um atrás do outro, do lado de fora do } \\
\text { círculo de cadeiras. Quando a música toca, todos } \\
\text { eles se movem na mesma direção em torno do } \\
\text { círculo de cadeiras. Quando a música para todos } \\
\text { buscam uma cadeira para se sentar. O objetivo do } \\
\text { grupo é fazer com que todos os participantes se } \\
\text { sentem nas cadeiras disponíveis. É permitido que } \\
\text { várias pessoas ocupassem a mesma cadeira, desde } \\
\text { que cada uma delas esteja em contato com a } \\
\text { cadeira com alguma parte de seu corpo. Se o grupo } \\
\text { atingir seu objetivo, o jogo recomeça com uma } \\
\text { cadeira a menos. }\end{array}$ \\
\hline O resgate & -2. & $\begin{array}{l}2^{\mathrm{a}} \text { Aula } \\
\text { (Primeiro } \\
\text { encontro) }\end{array}$ & $\begin{array}{l}\text { Nessa atividade os alunos são desafiados a } \\
\text { organizarem grupos e realizarem exercícios de } \\
\text { força, equilíbrio e resistência onde um depende do } \\
\text { outro para alcançar os objetivos propostos. }\end{array}$ \\
\hline $\begin{array}{l}\text { Passando o } \\
\text { bambolê }\end{array}$ & Bambolês & $\begin{array}{l}3^{\text {a }} \text { Aula } \\
\text { (Segundo } \\
\text { encontro) }\end{array}$ & $\begin{array}{l}\text { A turma é dividida em grupos de cerca de seis a oito } \\
\text { crianças. Os integrantes de cada grupo devem dar } \\
\text { as mãos, formando um círculo. Coloca-se, então, um } \\
\text { bambolê sobre as mãos unidas de dois integrantes } \\
\text { de cada grupo. O objetivo é fazer passar o bambolê } \\
\text { por todo o círculo de pessoas que o formam sem que } \\
\text { soltem as mãos em momento algum e sem deixar o } \\
\text { bambolê tocar no chão. }\end{array}$ \\
\hline A travessia & Cadeiras & $\begin{array}{l}4^{a} \text { Aula } \\
\text { (Segundo } \\
\text { encontro) }\end{array}$ & $\begin{array}{l}\text { Alunos divididos em grupos de } 6 \text {, cada grupo com } \\
\text { dois colchões, deverão colocá-los de maneira que } \\
\text { percorram uma distância determinada pelo } \\
\text { professor, sem colocar os pés no chão. }\end{array}$ \\
\hline $\begin{array}{l}\text { Subindo } \\
\text { redondo }\end{array}$ & Bambolês & $\begin{array}{c}5^{\mathrm{a}} \text { Aula } \\
\text { (Terceiro } \\
\text { encontro) }\end{array}$ & $\begin{array}{l}\text { Formar grupos de cinco alunos dispostos em } \\
\text { círculos, em torno dos bambolês. Pedir aos alunos } \\
\text { que apoiem os bambolês sobre seus pés, sem tocar } \\
\text { no chão, e que passem os braços sobre os ombros } \\
\text { dos companheiros (abraçados). O objetivo é } \\
\text { levantar o bambolê até o pescoço, sem tocá-lo com } \\
\text { as mãos. }\end{array}$ \\
\hline $\begin{array}{l}\text { Pulando todos } \\
\text { juntos }\end{array}$ & Cordas & $\begin{array}{l}6^{\mathrm{a}} \text { Aula } \\
\text { (Terceiro } \\
\text { encontro) }\end{array}$ & $\begin{array}{l}\text { Proposta ao grupo (três, quatro ou cinco alunos) a } \\
\text { tarefa de dar no mínimo três pulos seguidos dentro } \\
\text { da corda. Aumentar a quantidade de alunos e pulos } \\
\text { de modo a tornar a atividade mais coletiva possível. }\end{array}$ \\
\hline Bola quente & Bola & $\begin{array}{l}7^{\text {a }} \text { Aula } \\
\text { (Quarto } \\
\text { encontro) }\end{array}$ & $\begin{array}{l}\text { Organizar o grupo em círculo com todos os } \\
\text { participantes. Após iniciar a música, o mediador } \\
\text { entrega a bola para ser passada entre os } \\
\text { participantes. Ao parar a música, quem estiver com } \\
\text { a bola nas mãos deverá dizer seu nome e fazer um } \\
\text { movimento engraçado utilizando a bola. Antes de a } \\
\text { música recomeçar, pedir que todos repitam o } \\
\text { movimento do colega. O jogo continua até que todos } \\
\text { tenham dito o próprio nome. }\end{array}$ \\
\hline
\end{tabular}




\begin{tabular}{|c|c|c|c|}
\hline $\begin{array}{c}\text { Não deixe a } \\
\text { bola cair }\end{array}$ & Bola & $\begin{array}{l}8^{\mathrm{a}} \text { Aula } \\
\text { (Quarto } \\
\text { encontro) }\end{array}$ & $\begin{array}{l}\text { Encher uma bola e formar um círculo com o grupo. } \\
\text { O mediador joga a bola para o alto dentro do círculo } \\
\text { e chama algum aluno para tocá-la novamente para } \\
\text { o alto. Ao tocar a bola, esse aluno volta para o } \\
\text { círculo e chama outro colega para dar continuidade } \\
\text { ao jogo. Repete-se até que todos toquem a bola, } \\
\text { mas sem deixá-la cair. }\end{array}$ \\
\hline
\end{tabular}

Fonte: Jogos extraídos dos trabalhos de Civitate (2012), Fernández-Río et al. (2015) e Correia (2006).

As intervenções ocorreram nos horários dedicados às aulas de Educação Física, e por conta das constantes chuvas que ocorreram no período da pesquisa, todas as aulas/intervenções ocorreram ora em espaços cobertos destinados ao recreio, ora na sala de aula. Segue abaixo um quadro que mostra como foram organizadas metodologicamente as aulas:

Quadro 2 - Organização das aulas/intervenção.

\begin{tabular}{|c|c|}
\hline FASES: & AÇÕES: \\
\hline 10 MOMENTO: & Apresentação do jogo com os objetivos a serem alcançados. \\
\hline 20 MOMENTO: & Esclarecimento das regras para alcançar os objetivos. \\
\hline 30 MOMENTO: & Organização ${ }^{3}$ dos grupos de trabalho. \\
\hline 40 MOMENTO: & Vivência dos Jogos \\
\hline 50 MOMENTO: & Entrevista focal com os alunos no final das intervenções \\
\hline
\end{tabular}

Fonte: Elaborado pelo pesquisador

A coleta de dados foi efetuada por dois instrumentos: a observação sistemática e uma entrevista semiestruturada. A observação, é um procedimento que permite o exame dos fatos ou fenômenos que estão sendo estudados, sendo uma etapa imprescindível em qualquer tipo ou modalidade de pesquisa (SEVERINO, 2016). O foco da observação consistiu na interação dos alunos com deficiência intelectual com seus pares, na interação dos alunos com os jogos e o diálogo que eles estabeleciam diante da vivência dos jogos.

As entrevistas, por sua vez, foram realizadas com os alunos no final de cada intervenção, seguindo o seguinte roteiro: 1) a atividade feita permitiu a participação de todos os alunos? 2) houve diálogo entre os participantes? 3) foi possível ajudar o colega durante a atividade? 4) como vocês avaliaram a atividade de hoje? Para registrar as respostas dos alunos, utilizou-se um aparelho gravador de áudio, e para

\footnotetext{
3 O método na divisão dos grupos, dependendo do tipo de jogo, foi o agrupamento livre, com isto buscou-se não interferir nas escolhas dos alunos. Foram feitas apenas algumas restrições relativas às especificidades de alguns jogos, como o número mínimo de participantes por grupo, por exemplo.
} 
registrar as intervenções com os jogos cooperativos, utilizou-se uma máquina fotográfica. Os registros fotográficos foram usados com a finalidade de complementar as informações dos instrumentos de coleta de dados.

Os questionamentos presentes na entrevista tiveram como propósito não só coletar os dados relevantes para pesquisa, mas também conduzir os alunos a refletirem sobre suas atitudes na interação com o outro que the é diferente, e a partir daí auxiliá-los na tomada de consciência no sentido de que todos devem ter as mesmas oportunidades de aprendizagem, a despeito de sua condição física, cognitiva, sensorial ou social. Foi um movimento de ação-reflexão-ação.

Figura 2 - Ações esperadas na aplicação das entrevistas

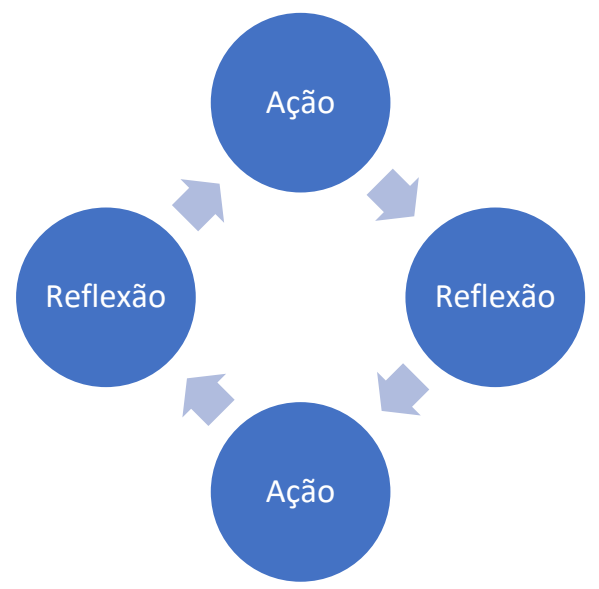

Fonte: Elaborado pelos autores da pesquisa

Utilizou-se como instrumento de registro o diário de campo, instrumento cujo propósito foi anotar dados relevantes durante a intervenção. Nesse sentido, o diário de campo permitiu sistematizar as experiências para posteriormente serem analisadas em conjunto com os resultados das entrevistas feitas com os alunos no final de cada intervenção.

Para analisar os dados provenientes das observações das entrevistas, serão tomados como referência o método de análise proposto por Lüdke e André (2017). Neste método, o primeiro passo consiste na construção de um conjunto de categorias descritivas construídas por meio de leituras sucessivas do material coletado. Após esse processo, a análise das categorias terá como foco desvelar mensagens 
implícitas, dimensões contraditórias, e temas sistematicamente "silenciados" (LÜDKE; ANDRÉ, 2017).

\section{Discussão dos Resultados}

No primeiro dia de intervenção, a princípio, foi explicado para os alunos que as aulas seriam conduzidas conforme a estrutura metodológica de uma aula convencional de Educação Física, porém, com algumas adaptações por conta da pesquisa. As adaptações seriam os registros fotográficos feitos durante as intervenções, bem como os registros de suas falas no final de cada intervenção.

Importa destacar que nesse dia surgiram algumas dificuldades na aplicação dos jogos por conta do espaço. Habitualmente as aulas ocorrem na quadra, no entanto, nesse dia chovia muito e a quadra não possui cobertura. Em virtude disso, foi utilizado um pequeno espaço coberto destinado ao recreio. Como esse espaço não oferecia condições para trabalhar com toda a turma de uma única vez, optou-se em dividir a turma em dois grupos, sendo que cada grupo vivenciou os dois jogos propostos para o dia, mas em grupos menores do que estava previsto. A ideia inicial era que todos os alunos pudessem vivenciar os dois jogos de forma coletiva, mas as condições não permitiram.

A primeira atividade chamava-se "Dança das cadeiras cooperativas". Nessa atividade, as cadeiras foram dispostas em círculo, com os acentos voltados para fora e com uma a menos do que o número de participantes. Os alunos posicionaram-se, um atrás do outro, do lado de fora do círculo de cadeiras. Quando a música tocava, todos eles se moviam na mesma direção em torno do círculo de cadeiras. Quando a música parava, todos deveriam buscar uma cadeira para se sentar. O objetivo do grupo foi fazer com que todos os participantes se sentassem nas cadeiras disponíveis. Foi permitida que várias pessoas ocupassem a mesma cadeira, desde que cada uma delas estivesse em contato com a cadeira com alguma parte de seu corpo. Toda vez que se parava a música uma cadeira era retirada. 
Figuras 3 e 4 - Dança das cadeiras cooperativa
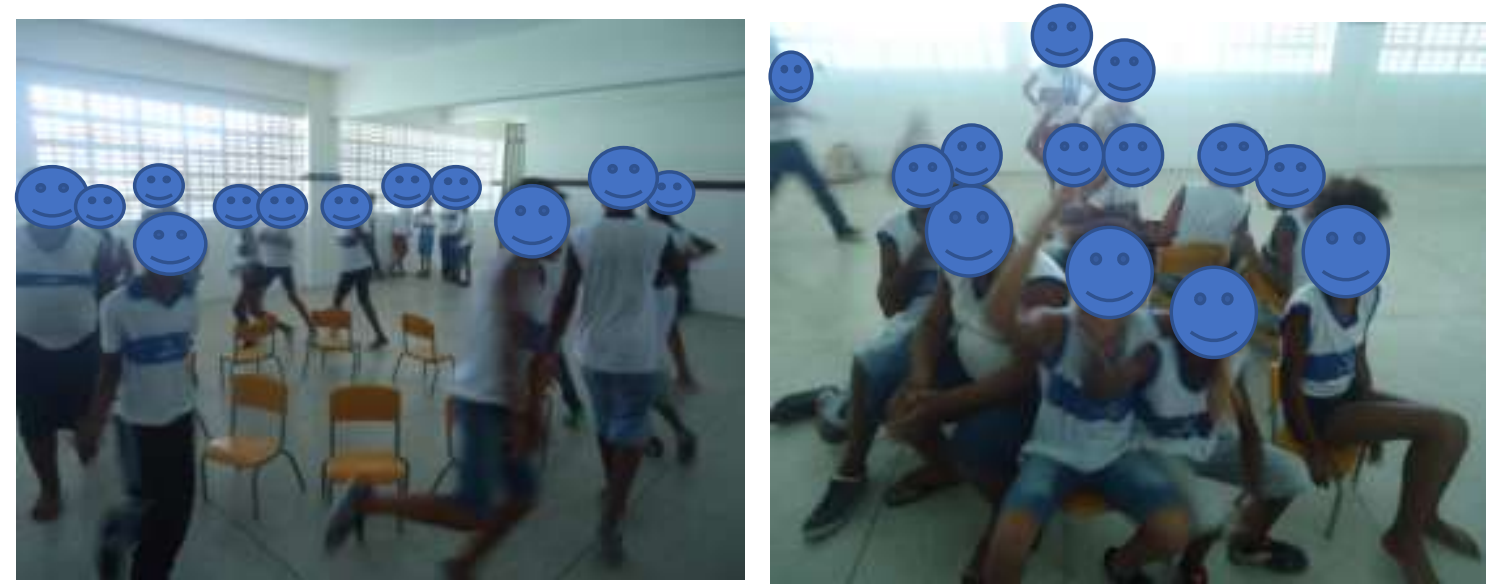

Fonte: acervo dos pesquisadores

$\mathrm{Na}$ figura 3 observa-se o momento em que eles circulavam ao redor da cadeira ao som da música, e na figura 4 o momento em que a música foi interrompida e eles foram desafiados a sentar-se nas cadeias sabendo que o número de delas era menor do que o número de participantes. Nessa mesma figura é possível visualizar alguns alunos compartilhando as cadeiras eu atitude de auxílio.

Sobre o primeiro jogo aplicado, a princípio, eles encontraram dificuldades em compartilhar a cadeira com o colega, isso porque eles tinham como referência uma versão dessa brincadeira na qual quem não conseguisse sentar era excluído. Esse fato fez com que eles demostrassem um comportamento de ansiedade em querer sentar primeiro que seus colegas, mas com o tempo, vendo que não havia exclusão das pessoas que não conseguissem sentar, foram assumindo um comportamento mais cooperativo, especialmente com os alunos que tinham deficiência. Nesse sentido, o que ficou em maior evidência nessa atividade foi a atitude de auxilio mútuo entre os alunos, como se observa na fala de Lavínia quando questionada como ela auxiliou seus colegas:

- "Eu ajudei Rute, Raquel e Marta porque elas sentaram em meu colo." ·

Nesse sentido, Sikora et al. (2017, p.104-105) afirmam na conclusão de sua pesquisa que durante a prática cooperativa, as diferenças entre pares, bem como as distintas necessidades educativas especiais, não são evidenciadas de forma negativa, haja vista que a proposta elementar do jogo cooperativo é o auxílio mútuo e a união 
das capacidades e potencialidades de cada um dos envolvidos, para uma meta comum.

Resultados semelhantes chegaram Loureiro, Vargas e Carvalho (2015) em seu estudo realizado com participação de dez pessoas com deficiência intelectual que frequentam um centro de atendimento a pessoas com deficiência e altas habilidades. Durante a intervenção utilizando jogos cooperativos, os autores constaram que na prática dos jogos houve uma ajuda mútua entre os participantes na realização das atividades, independente das suas limitações, psíquica ou física, predominando a união, o respeito, o espírito de grupo, portanto, pode-se inferir que a inclusão social este presente, pois houve uma participação de todos os envolvidos.

No segundo jogo, eles foram desafiados a demonstrar equilíbrio, força e resistência em um jogo chamado "Ginástica Acrobática". Nesse jogo, a princípio, apresentaram-se a eles, utilizando-se um aparelho celular, algumas imagens de ginástica acrobática para que eles se inspirassem de exercícios de ginástica acrobática. Em seguida, esclareceram-se algumas regras do jogo e solicitou-se que eles se organizassem em grupos e tentassem agora usando a criatividade criar novas possibilidades de exercícios a partir dos que eles tinham visualizado. Na figura 5 e 6 verifica-se a produção de alguns grupos.

Figuras 5 e 6 - Ginástica Acrobática
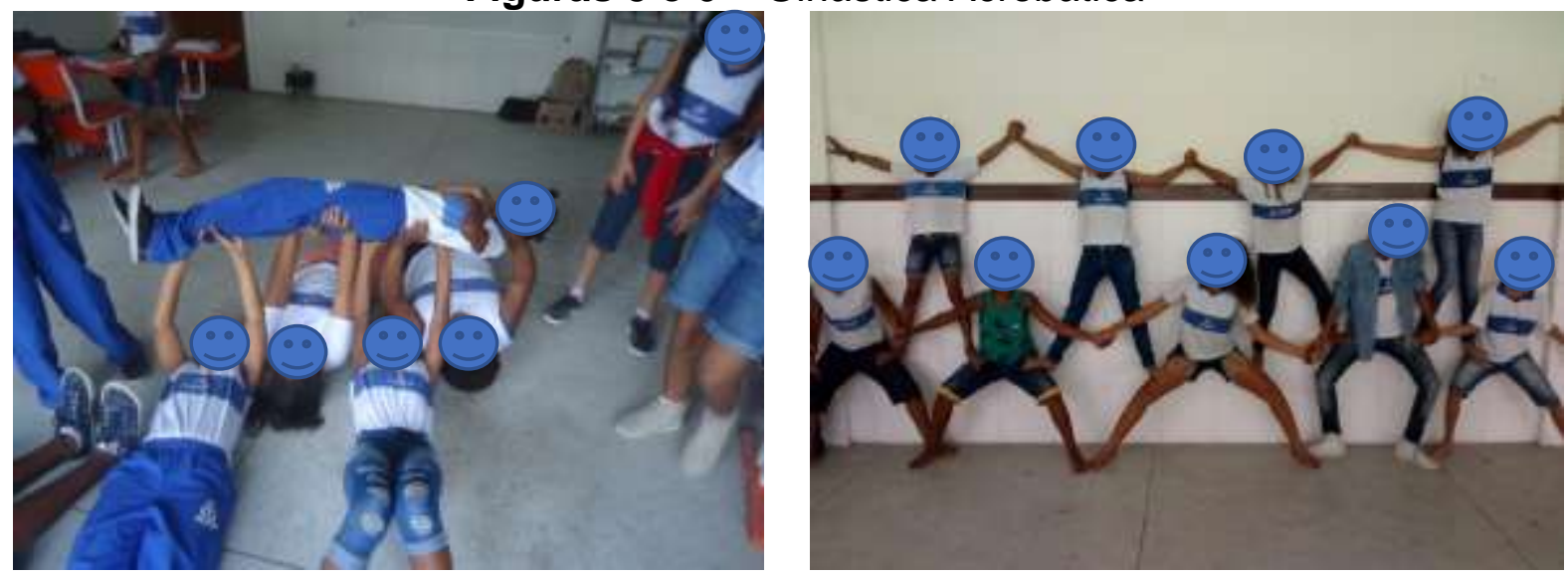

Fonte: acervo dos pesquisadores

Todos participaram da atividade, porém alguns se envolveram mais que os outros. Além disso, não foi observada nenhuma atitude de rejeição por parte de algum aluno para com o outro, e ficou evidente pela forma como eles dialogaram e 
se articularam para cumpri os objetivos do jogo, que eles entenderam que o sucesso do grupo naquela atividade dependia do esforço de todos, pois para manterem-se nas posições propostas, eles precisaram do auxilio um do outro. Ou seja, houve uma interdependência positiva entre os integrantes do grupo. Nesse sentido, Brotto (2013, p.67) afirma que os jogos cooperativos "são jogos nos quais o esforço cooperativo é necessário para se atingir um objetivo comum e não para fins mutuamente exclusivos". Os alunos com deficiência participaram ativamente da tarefa. Uma delas inclusive, na Figura 5 está sendo suspensa pelos seus colegas.

$\mathrm{Na}$ entrevista realizada no final da aula, quando solicitados que avaliassem as atividades, uma parte dos alunos afirmou que estavam acostumados com atividades onde quem perdesse saía, mas jogar dessa forma também era divertido.

O primeiro jogo aplicado no segundo dia foi "Passando o Bambolê". Nessa atividade, a turma se dividiu em grupos de cerca de doze alunos. Os integrantes de cada grupo deram as mãos, formando um círculo. Colocou-se, então, um bambolê sobre as mãos unidas de dois integrantes de cada grupo. O objetivo do jogo foi fazer passar o bambolê por todo o círculo de alunos sem que soltem as mãos em momento algum e sem deixar o bambolê tocar no chão. Como se observa na figura 7, o jogo segue em um estágio inicial com apenas um bambolê, em um momento posterior figura 8 -, o jogo segue em um estágio mais evoluído com cinco bambolês.

Figuras 7 e 8 - Passando o Bambolê
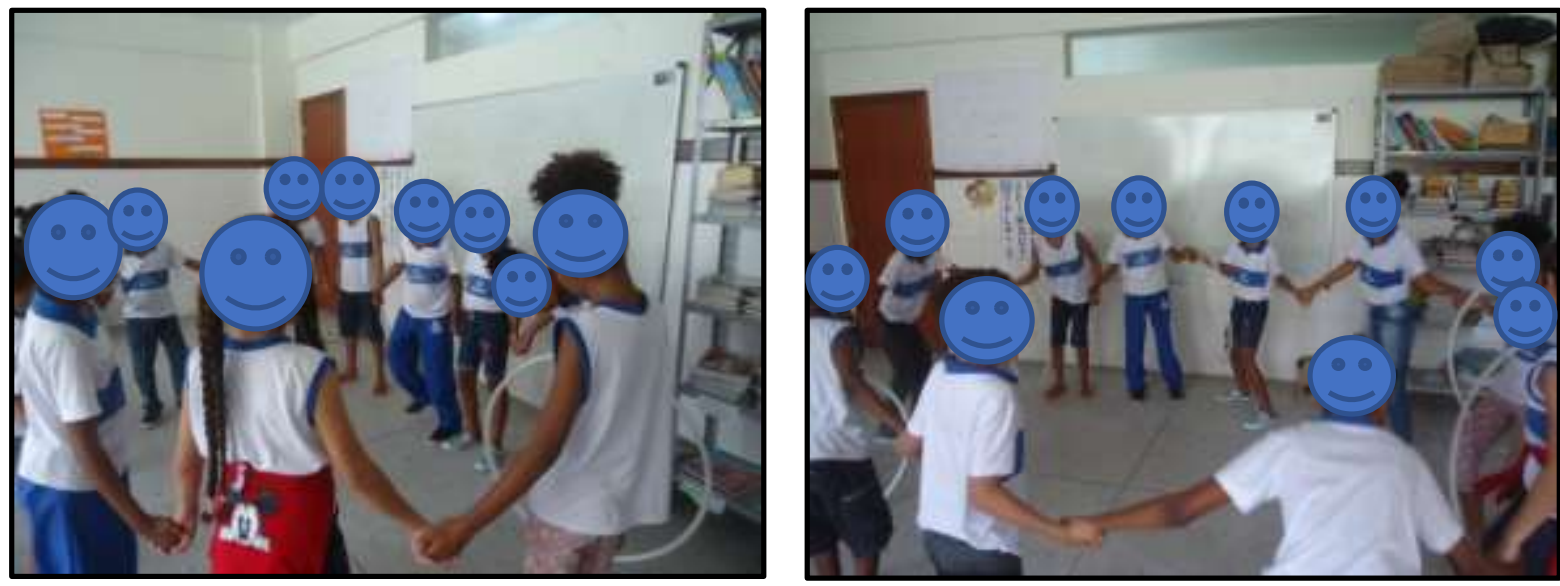

Fonte: acervo dos pesquisadores

Foi possível observar, em diversas circunstâncias, um constante diálogo entre os alunos sobre os desafios impostos pelo jogo, especialmente quando 
alguns destes demonstravam dificuldades na execução da tarefa, como foi o caso das alunas com deficiência, pois, ambas apresentam um leve comprometimento motor fato que motivou o mediador a fazer algumas adaptações durante o jogo. Omeñaca e Ruiz apud Fernández-Río et al. (2015) descrevem que os jogos cooperativos promovem condutas de apoio e estimula a comunicação entre os participantes. Alguns estudos, inclusive, destacam que a vivência de jogos em que se predomina a cooperação favorece o desenvolvimento de habilidades comunicativas em crianças com Transtorno do Espectro Autista, reduzindo dessa forma seu isolamento social (FRANCISCO, 2014; LOUREIRO, VARGAS, CARVALHO, 2015).

Ao fim da atividade, quando questionados sobre a importância no diálogo nesta atividade, Mateus, João e Pedro respectivamente responderam:

- "Precisei conversar com meu colega para ensinar como ele deveria passar o bambolê de forma correta."

- "Eu estava toda hora: mergulha João, mergulha João!"

- "Eu conversei com Paulo para ajudar ele a passar para o bambolê porque ele não estava conseguindo."

A fala destes alunos chamou a atenção pelo fato de que em outras circunstâncias nas aulas, os alunos "mais habilidosos" tinham por costume chamar os "menos habilidosos" de nomes pejorativos e depreciativos como "burro", "ignorantes", entre outros. Tais ocorrências evidenciavam-se quando os referidos alunos não conseguiam executar uma tarefa. Assim, o auxilio dado aos colegas menos hábeis, demonstrando respeito e atitudes positivas, revela uma mudança de atitude, promovida, possivelmente, pela forma cooperativa de jogar. Nesse sentido, Soler (2005), Correia (2006) e Brotto (2013) apontam em seus estudos que os jogos cooperativos diminuem as chances de experiências negativas durante as aulas, porque o foco deixa de ser o resultado e passa a ser o processo, e os erros passam a ser uma oportunidade de apoio para os demais.

Nessa mesma perspectiva, Ferri (2012) evidenciou em sua pesquisa a importância dos jogos cooperativos como uma possibilidade de inclusão dos alunos em relação ao ensino de Educação Física Escolar, contribuindo positivamente nas relações professor-aluno e aluno-aluno.

O segundo jogo proposto foi "A travessia". Nesse jogo, os alunos foram divididos em grupos de cinco (5), cada grupo com três bambolês. O objetivo 
do jogo foi colocar os bambolês de maneira que percorressem uma distância determinada, sem colocar os pés fora do perímetro do bambolê. Outro participante deveria por um bambolê a frente do grupo para que eles percorressem o caminho estabelecido, como se observa na figura 9 no momento inicial, e na figura 10 no momento final, onde eles estão próximos de alcançar o objetivo do jogo.

Figuras 9 e 10 - Travessia/início do jogo
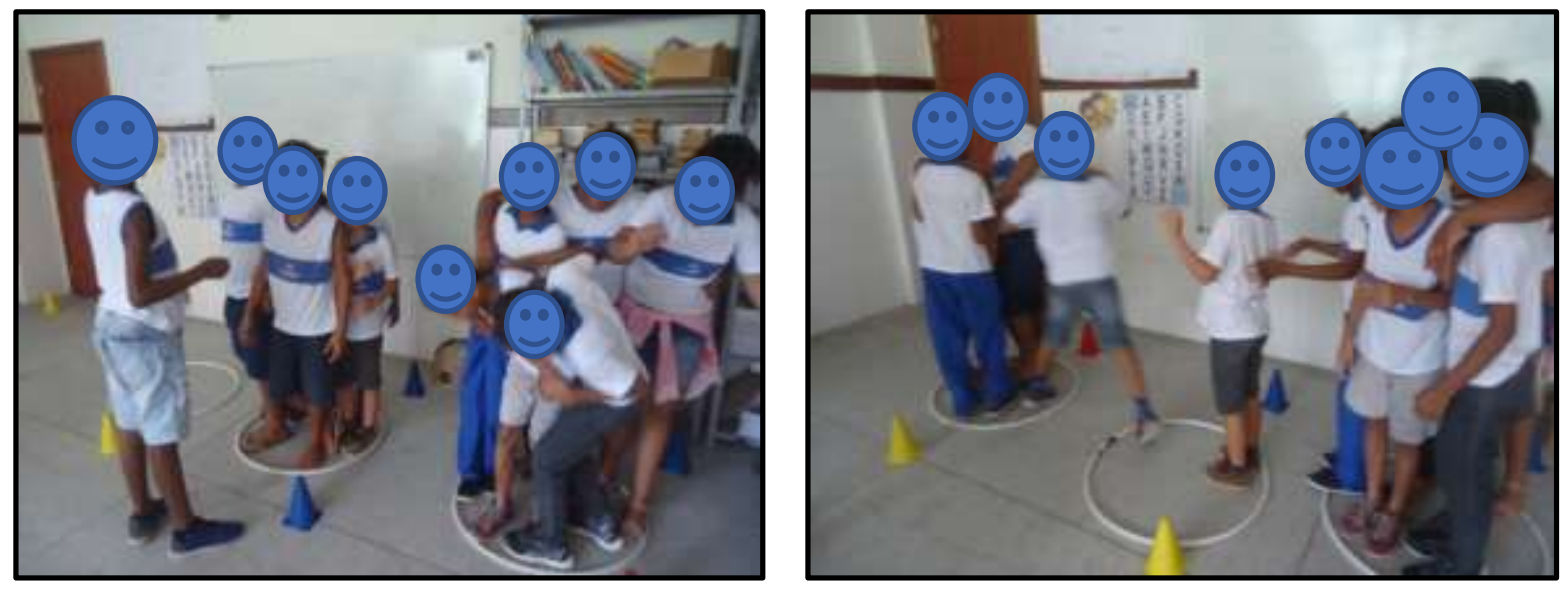

Fonte: acervo dos pesquisadores

Inicialmente, foi desafiante para eles se manterem equilibrados em grupos de quatro a três alunos em um pequeno espaço limitado pelo bambolê. O momento que mais houve interação entre eles foi quando tiveram que decidir quem sairia do bambolê primeiro para passar para o outro bambolê. Resolvido esse conflito, eles utilizaram como estratégia abraçar-se para que ninguém saísse do espaço, como se observa na figura 3. Caso alguns dos alunos pisassem fora do perímetro do bambolê mais de três vezes, eles retornariam ao ponto inicial.

Os obstáculos impostos pelo jogo os estimularam a pensarem coletivamente em estratégias para superá-los. Porém com uma significativa diferença, o foco não estava em vencer um adversário, mas superar um desafio coletivamente, onde o esforço de cada um foi essencial. Ademais, o destaque dessa atividade fica por conta também de um dos valores humanos essenciais para fomentar a inclusão: a solidariedade. Mesmo apresentando algumas limitações na hora de compreender a atividade, as alunas com deficiência puderam participar porque foram auxiliados pelos demais. Quando questionados se eles em algum momento da atividade tiveram que 
auxiliar seus colegas, Lucas, Marcos, Mateus, Paulo e Joana respectivamente responderam:

- "Eu puxei Ana e puxei Marcos para eles não caírem fora do bambolê".

- "Tive que segurar Ana para que ela não caísse".

- "Tive que segurar meus amigos para eles não caírem".

Verifica-se nestas falas que as situações proporcionadas pelo jogo favoreceram o desenvolvimento de atitudes positivas para com os colegas. Estudos vêm apontando que os Jogos Cooperativos contribuem, sobretudo, como ferramenta que fomenta a aprendizagem de valores e princípios como a solidariedade, o diálogo, o companheirismo, a tolerância, entre outros (ABRAHÃO, 2004; BLANCO 2007; BROTTO, 2013; MOREIRA, 2017; FIDALGO, 2015 e MONTEIRO, 2006).

Ainda sobre esse aspecto, Brotto (2013, p.67) afirma que "jogando cooperativamente temos a chance de considerar o outro como um parceiro, um solidário, em vez de tê-lo como adversário, operando interesses mútuos e priorizando a integridade de todos." Atitudes de solidariedade e de generosidade são fundamentais para uma convivência em grupo e para formação de uma consciência inclusiva. Concernente à participação das alunas com deficiência, nessa atividade, observou-se que nessa fase da intervenção, a integração delas ao grupo era evidente e marcante. Seu entusiasmo e envolvimento eram constantes. Muito afetuosas e empolgadas, demostraram prazer em participar dos jogos e interagir com seus colegas. Seus colegas, por sua vez, a acolhiam com uma maior receptividade.

No final, quando questionados no tocante a avaliação que faziam da aula, Lucas, Joana, Maria, Rute e Marcos, respectivamente responderam:

- "Foi massa porque foi cooperativa".

- "Achei a atividade boa porque quando alguém erra não sai".

- "Achei a atividade boa porque ninguém sai".

- "Gostei da atividade porque era divertida".

- "A atividade foi boa porque ajudei meus colegas".

A avaliação positiva dos alunos em relação aos jogos cooperativos foi por conta de uma das principais características deste modelo jogo; isto é, a não exclusão. Soler (2005) descreve que os jogos cooperativos possuem diversas características libertadoras, que são muito coerentes com o trabalho coletivo, dentre estas eles 
libertam da eliminação. Segundo o autor "o esboço do jogo cooperativo busca a integração de todos" (p.139). Isso faz com que os jogos cooperativos, por evitarem situações de exclusão, se aproximem das propostas inclusivas.

Há de se destacar, ainda, que os jogos vivenciados nesse dia motivaram a participação inclusive daqueles que anteriormente não demostravam muito interesse nas aulas práticas de Educação Física. Tais alunos sempre são um desafio para os professores, visto que, na maioria das vezes, eles se julgam incapazes, consequentemente desenvolvem um sentimento de impotência e humilhação que os leva a aceitar sua condição e abandonam qualquer tentativa de aprendizado. Essas crianças, em sua maioria, são os que ainda não conseguiram alcançar determinada habilidade motora; os que estão em situação de sobrepeso; as meninas; e os que apresentam algum tipo de déficit sensorial, motor ou cognitivo.

Observou-se essa realidade sendo modificada na medida em que os alunos começaram a demonstrar interesse em participar dos jogos, e sem nenhum tipo de resistência ou discriminação por parte dos outros alunos, eles foram aceitos e acolhidos nos grupos. Resultados semelhantes, envolvendo alunos com deficiência em iteração com seus pares em jogos e brincadeiras cooperativas, foram encontrados nos estudos de Francisco (2014), Nascimento, Scapim e Silveira (2010), Oliveira e Fischer (2016), Sikora et al. (2014), Loureiro, Vargas e Carvalho (2015).

No terceiro dia, para realização do primeiro jogo, eles foram divididos em grupos de cinco (5), sendo que cada grupo recebeu um bambolê. Os alunos então deveriam apoiar os bambolês sobre seus pés, sem tocar no chão, e deveriam passar os braços sobre os ombros dos colegas. O desafio foi levantar o bambolê até 0 pescoço, sem tocá-lo com as mãos.

Inicialmente, os alunos não se deram conta que para cumpri o objetivo do jogo eles tinham que auxiliar um ao outro, portanto, precisariam dialogar e montar uma estratégia. Foram diversas tentativas que acabaram sem o resultado esperado, isso porque eles ainda estavam jogando de forma individual. Essa situação muda quando em um determinado grupo um aluno resolve parar a atividade e planejar como deveriam proceder para cumprir o que tinha sido proposto pelo jogo. Mesmo enfrentando dificuldades, o grupo conseguiu realizar a atividade e passaram a auxiliar 
os outros grupos. No entanto, nem todos conseguiram e mostraram-se desmotivados para prosseguir.

Nessa sequência, houve então uma pequena parada na aula para reflexão sobre o motivo que os levou a abandonar a atividade. Em linhas gerais, eles relataram que o jogo era muito difícil. Diante dessa situação, foi proposta uma discussão sobre a questão do erro e das frustrações. Procurou-se, nesse caso, deixar claro para os alunos que o mais importante às vezes não é o resultado de uma ação, mas as aprendizagens que podem ser construídas nesse processo. Feito isso, flexibilizou-se junto com os alunos algumas regras do jogo com isso alguns deles tentaram realizar o jogo e conseguiram logra êxito. A participação das alunas com deficiência nessa atividade foi positiva, além de serem acolhidas pelo seu grupo, demonstraram satisfação e entusiasmo na vivência do jogo.

Outro ponto a ser destacado foi às atitudes de auxílio que foram significativas e proporcionou experiências positivas, promovendo relações empáticas, cordiais e construtivas entre os participantes. Nesse sentido, segue a fala de dois alunos, Marcos e Marta, relatando em que contexto foi possível ajudarem os colegas:

- "Houve diálogo quando eu não estava conseguindo e João mandou pôr o pé por baixo do bambolê".

- "Teve diálogo quando eu fui ajudada a colocar o bambolê no joelho para passar".

Figuras 11 e 12 - Pulando todos juntos
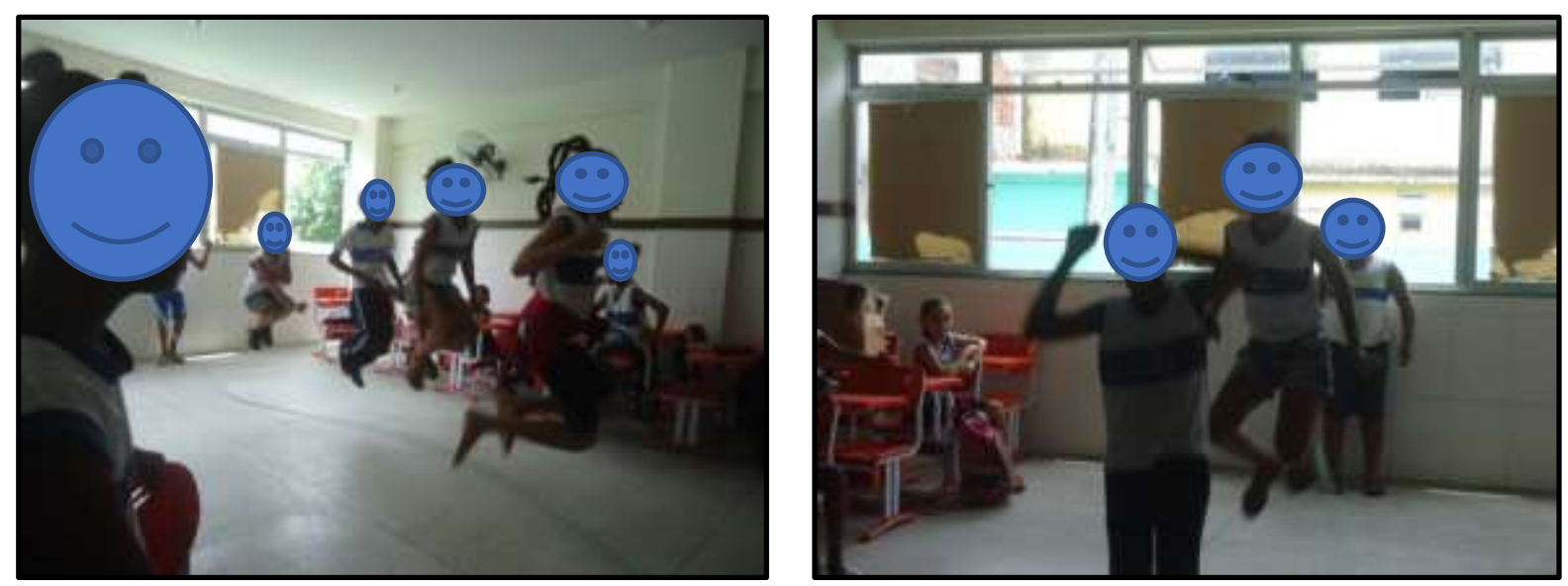

Fonte: acervo dos pesquisadores

Fazendo uma análise geral, a atividade proposta neste dia mostrou-se inclusiva, pois todos conseguiram se envolver de forma ativa e não houve 
nenhum tipo de impedimento que limitasse a participação dos alunos, inclusive aqueles com deficiência, que por diversas circunstâncias foram auxiliados pelos seus colegas. Pesquisas, como a de Loureiro, Vargas e Carvalho (2015), envolvendo crianças com deficiência intelectual, afirmam que as intervenções feitas com esse público utilizando os jogos cooperativos contribuíram para estreitar as relações sociais entre estes indivíduos e o grupo a qual estavam inseridos, uma vez que houve interdependência na vivência dos jogos, ou seja, um dependia do outro para alcançar êxito na atividade, consequentemente tornou o diálogo entre eles constante.

A segunda atividade foi a "Pulando todos juntos". Foi proposta ao grupo de quatro alunos a tarefa de dar no mínimo dez pulos seguidos dentro da corda. Inicialmente, foi proposto começar com duas pessoas e conforme fosse conseguindo com esse número de pessoas e aumentando gradativamente até tentar incluir o maior número de pessoas na corda, incluindo um aluno de cada vez. Para que um determinado número de alunos pulando corda fosse válido, eles deveriam sempre dar no mínimo dez pulos consecutivos, conforme se observa na figura 11 onde eles já se encontram em um estágio evoluído do jogo consegue pular em quatro e na figura 12 tem-se a uma das alunas com deficiência pulando junto com outra colega.

Esse jogo precisou ser adaptado por conta de alguns alunos que ainda não tinham alcançado a habilidade de pular a corda. Nesse caso, o desafio para eles foi realizar saltos simples com a corda parada. Feito essa adaptação, a atividade tornouse mais inclusiva e todos puderam participar (Figura 13).

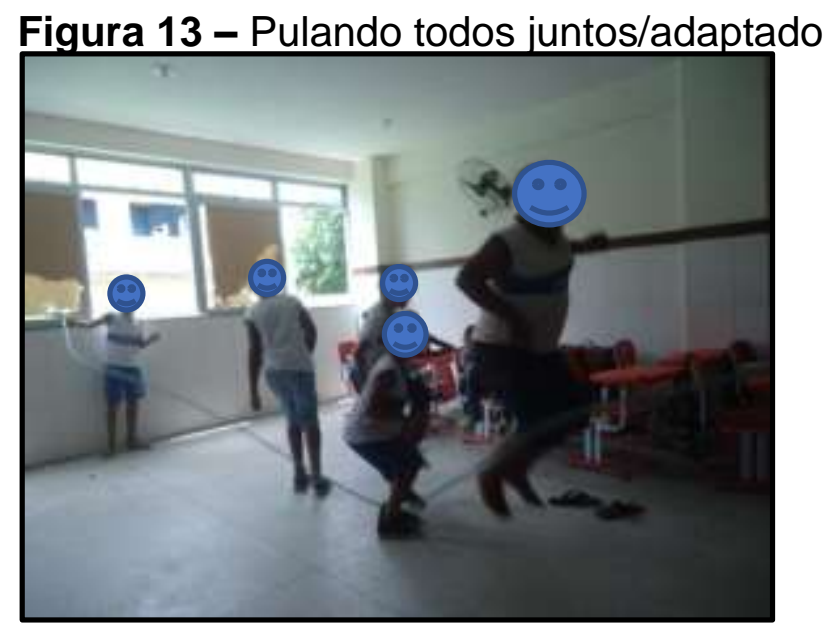

Fonte: acervo dos pesquisadores 
No último dia, foram realizados dois jogos em sala com auxílio de músicas. No primeiro jogo, eles foram organizados em um círculo, onde deveriam passar uma bexiga entre todos os participantes enquanto uma música era tocada. Quando essa música parasse, o aluno que estivesse com a bola na mão deveria retirar um desafio em uma caixa e executar. Foram tomados cuidados com os desafios para não expor os alunos a situações vexatórias, portanto, foram escolhidas atitudes afetivas como dar abraços, comprimentos, entre outros (Figura 14).

Figura 14 - Bola quente

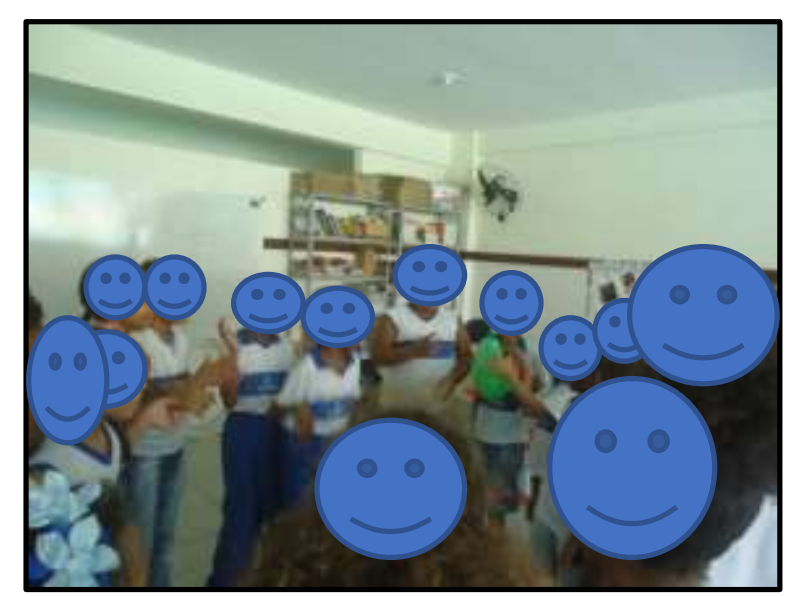

Fonte: acervo dos pesquisadores

O segundo jogo foi "Não deixe a bola cair". O jogo se desenvolveu da seguinte forma: uma bexiga foi jogada para o alto dentro de um círculo e foi chamado o nome de um aluno para tocá-la novamente para o alto. Ao tocar a bola, esse aluno volta para o círculo e chama outro colega para dar continuidade ao jogo. Repete-se até que todos toquem a bola, mas sem deixá-la cair (Figura 15). 
Figura 15 - Não deixe a bola cair

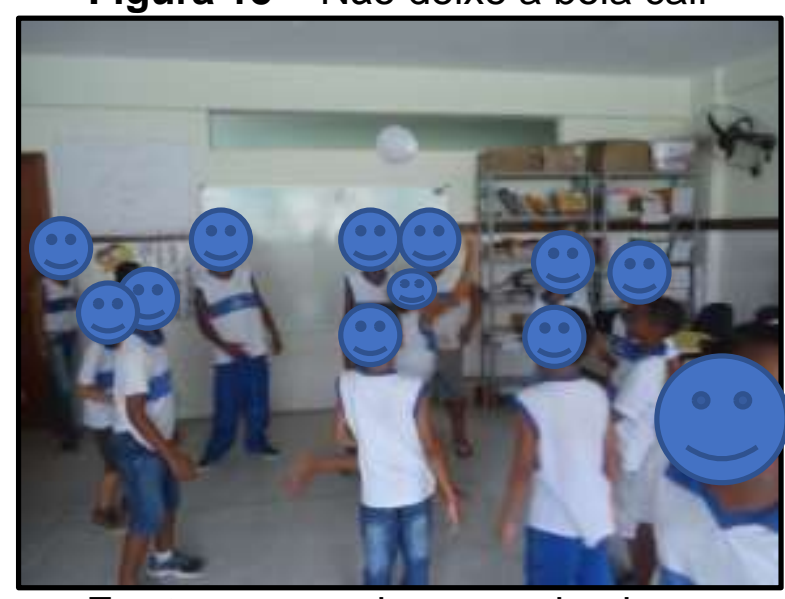

Fonte: acervo dos pesquisadores

Durante a realização dos dois jogos, o que ficou mais em evidência foi o envolvimento dos alunos na atividade. Existia um clima que favorecia a aprendizagem e os conflitos foram mínimos. As atitudes de tentar ridicularizar o colega - fato frequente em outras circunstâncias - não foram constatadas, e na interação entre eles, observaram-se atitudes de cooperação, sobretudo, com os menos hábeis.

No final da intervenção, em especial na última pergunta, onde avaliam a participação deles nos jogos, ficou notório que a não exclusão, ou seja, o fato de perder e não ter que sair da atividade, tornou o jogo mais interessante para eles, como se observou nas falas de Matias, Paulo, Tomé e Marta:

- "Achei legal porque a pessoa não sai e era cooperativa".

- "Acho a atividade cooperativa melhor porque as pessoas não ficam sem brincar".

- "Achei a atividade boa porque ninguém sai".

- "Eu prefiro as atividades que não tem exclusão porque ninguém sai".

Fernández-río et al. (2015) destacam que as atividades integrativas e participativas na qual todos os participantes do grupo desempenham uma tarefa, produzem efeitos positivos, como a não discriminação e a não eliminação. Não se descrimina porque não há uma classificação entre quem é "ruim" ou "bom", entre os vencedores e os perdedores, entre meninos e meninas. A tendência é que os participantes não busquem se destacar perante seus colegas ou adversários, mas, sim, buscar o prazer propiciado pela experiência de vivenciar os desafios da atividade, contando com a ajuda de seus colegas (FERNÁNDEZ-RíO, et al. 2015). 
A não eliminação, por sua vez, ocorre porque o erro é encarado em outra perspectiva, isto é, como uma possibilidade de continuar jogando e experimentando. O erro passa a ser encarado com uma etapa de um processo de exploração na qual é possível criar e testar uma infinidade de respostas para os problemas motores apresentados. Nesse caso, o erro podem revelar informações sobre a atividade e sobre os sujeitos envolvidos, portanto, não devem ser confundidos com fracasso nem com vergonha, desse modo, aqueles que por circunstâncias adversas foram privados de experiências motoras tornando-se mais necessitados e menos habilidosos, tem uma maior acesso as atividades, porque não são eliminados ou marginalizados (ou automarginalizados) devido às imposições que privilegiam a eficiência em prol dos resultados (FERNÁNDEZ-RíO, et al. 2015).

Finalizada essa seção, trago alguns desafios desta pesquisa. $O$ primeiro que gostaria de pontuar foi a resistência de alguns alunos com os Jogos Cooperativos, visto que muitos estavam acostumados com jogos e brincadeiras em que a competição é um elemento central. No entanto, conforme eles refletiam sobre outras possibilidades de jogar cooperativamente, eles passaram demostrar um maior interesse nessa prática corporal.

Um segundo desafio que destaco desta pesquisa foi a dificuldade nas avaliações. Muitos se mostraram inibidos durante as entrevistas. Alguns alunos inclusive não se posicionaram sobre sua participação. Outro desafio foi a impossibilidade de realizar as atividades em espaços adequados, ou seja, na quadra. Isso ocorrei porque no período da pesquisa choveu em dias alternados, isso impossibilitou o uso da quadra pois a mesma não é coberta.

O fato de assumir duas posições durante a intervenção (professor e pesquisador) foi também um grande desafio. Embora reconheça que não se pode dissociar a profissão docente com a função de pesquisador. Como assinala Freire (1996): não existe o ensino sem pesquisa e a pesquisa sem ensino. Ou seja, a pesquisa faz parte da essência do docente, pois, a busca, o questionamento, a pesquisa e a reflexão são elementos essenciais do fazer docente.

\section{Considerações Finais}


Pretendeu-se com essa pesquisa compreender como os jogos cooperativos podem contribuir para inclusão dos alunos com deficiência nas aulas de Educação Física. Nesse caso, revelou-se como uma possibilidade de conteúdo escolar que atende aos princípios da educação inclusiva. Pois, percebeu-se uma maior participação dos alunos com deficiência nas aulas. A interação com seus pares ocorreu de forma amistosa e as ocorrências de rejeição foram significativamente reduzidas. Pressupõe-se, que interagindo cooperativamente, os alunos são conduzidos a perceber que todos têm potencialidades. Reduzindo, assim, concepções equivocadas de que as pessoas que apresentam limitações motoras, sensoriais, cognitivas, entre outras, são incapazes e ineficientes.

\section{Referências}

ABRAHÃO, Sérgio Roberto. A relevância dos jogos cooperativos na formação dos professores de Educação física: uma possibilidade de mudança paradigmática. 2004. 127 f. Dissertação (Mestrado em Educação) - Universidade Federal do Paraná, Curitiba, 2004. Disponível em: < https://acervodigital.ufpr.br/bitstream/handle/1884 /27945/R\%20-\%20D\%20\%20SERGIO\%20ROBERTO\%20ABRAHAO.pdf?sequence $=1$ \&isAllowed $=\mathrm{y}>$. Acesso em: 1 de junho. 2018.

BLANCO, Marcilene Regina. Jogos Cooperativos e Educação Infantil: limites e possibilidades. 2007. 181 f. Dissertação (Mestrado em Educação) - Universidade São Paulo, São Paulo, 2007. Disponível em: < http://www.teses.usp.br/teses/disponiveis /48/48134/tde-10122007-155211/ptbr.php>. Acesso em: 1 de junho. 2019.

AMERICAN ASSOCIATION ON MENTAL RETARDATION. Retardo mental: definição, classificação e sistemas de apoio. Tradução M. F. Lopes. 10. ed. Porto Alegre: Artmed, 2006.

BRASIL. Ministério da Educação. (2017). Base Nacional Comum Curricular. Disponível em: <http://basenacionalcomum.mec.gov.br/images/BNCC_El_EF_11051 8_versa ofinal_site.pdf >Acesso em 18 de ago. de 2020.

BROTTO, Fábio Otuzi. Jogos cooperativos: o jogo e o esporte como um exercício de convivência. 4. ed. São Paulo: Palas Athenas, 2013.

CIVITATE, Héctor. 505 Jogos cooperativos e competitivos. 4 ed. Rio de Janeiro: Sprint, 2012

CORREIA, Marcos Miranda. Trabalhando com jogos cooperativos. 4. ed. Campinas: Papirus, 2006. 
DUBOC, Thaís Oliveira. A percepção dos Estudantes Acerca da Inclusão dos Alunos com Deficiência nas Aulas de Educação Física. 2019. Dissertação (Mestrado em Educação) - Universidade do Estado da Bahia, Salvador 2019. Disponível em: < http://www.saberaberto.uneb.br/handle/20. 500.11896/1010>. Acesso em: 15 de jul. de 2020.

FERRI, Marta Helena Suzin Marini. Jogos cooperativos: recurso de inclusão na Educação Física. 2012. 128 f. Dissertação (Mestrado em Educação) - Universidade do Oeste de Santa Catarina. Joaçaba, 2012. Disponível em: < https://sucupira.capes.gov.br/

sucupira/public/consultas/coleta/trabalhoConclusao/viewTrabalhoConclusao.jsf?popu $\mathrm{p}=$ true\&id_trabalho=113820>. Acesso em: 1 de junho. 2019.

FERNÁNDEZ-RÍO, Javier. et al. Atividades e jogos cooperativos. Rio de Janeiro: Vozes, 2015.

FIDALGO, MARIO CERDEIRA. Cartografia dos jogos cooperativos nas aulas de Educação Física. 2015. 124 f. Dissertação (Mestrado em Educação) - Universidade Federal do Paraná, Curitiba, 2015. Disponível em: <https://sucupira.capes.gov.br /sucupira/public/consultas/coleta/trabalhoConclusao/viewTrabalhoConclusao.jsf?pop up=true\&id_trabalho=2501944>. Acesso em: 22 de junho. 2019.

FRANCISCO, patrícia Andreia Martins. Promoção de competências sociais através de Jogos Cooperativos na criança com Síndrome de Asperger: estudo de caso. 2014. 236 f. Dissertação (Mestrado em Educação) - Instituto Politécnico de Coimbra. Coimbra, 2012. Disponível em: < https://comum.rcaap.pt/bitstream/10400.26/12724/1/ PATRICIA_FRANCISCO.pdf>. Acesso em: 1 de junho. 2019.

FREIRE, P. Pedagogia da Autonomia: saberes necessários à prática educativa. São Paulo: Paz e Terra, 1996

FURTADO, O. L. P. DA C.; MORATO, M. P.; GUTIERREZ, G. L.; ALVES, M. L. T. A participação de jovens com deficiência visual em aulas de Educação Física: experiências na rede regular e em instituições especializadas. Pensar a Prática, v. 22, 18 abr. 2019.

LOUREIRO, Renan; VARGAS, Leandro Silva; CARVALHO, Nathan Ono. Jogos cooperativos como ferramenta de inclusão social da pessoa com deficiência intelectual. XIX Conbrace VI Conice: ANAIS DO XIX CONGRESSO BRASILEIRO | CONBRACE IV CONGRESSO INTERNACIONAL DE CIÊNCIAS DO ESPORTE DO ESPORTE, [s.l], p. 1-10, 2015. Disponível em: http://congressos.cbce.org.br/index.php/conbrace2015/6conice/paper/download/735 7/3664. Acesso em: 25 jul. 2020.

LÜDKE, Menga; ANDRÉ, Marli E.D.A.. Pesquisa em educação: Abordagens Qualitativas. 2. ed. Rio de Janeiro: E.P.U, 2017. 
MENDONÇA, Débora de; FLAITT, Maura da Silva. Educação física adaptada. São Paulo: Ciranda Cultural, 2013.

MONTEIRO, Fabricio Pomponet. Transformação das aulas de Educação Física: uma intervenção através dos jogos cooperativos. 2006. 222 f. Dissertação (Mestrado em Educação Física) - Universidade Estadual de Campinas, Campinas 2006. Disponível em:<bdtd.ibict.br/vufind/Record/CAMP_3b7bbc4fda7864e4123d80a 351d3c37>. Acesso em: 1 de junho. 2019.

MOREIRA, LAURA MARTINS. Jogos cooperativos e autorregulação da aprendizagem nas aulas de Educação Física. 2017. 93 f. Dissertação (Mestrado em Educação) - da Universidade do Vale do Sapucaí, Pouso Alegre, Minas Gerais, 2017.

Disponível em:

https://sucupira.capes.gov.br/sucupira/public/consultas/coleta/trabalho

Conclusao/viewTrabalhoConclusao.jsf?popup=true\&id_trabalho=5374450 >. Acesso em: 22 de junho. 2020.

NASCIMENTO, Graciele Seleguim; SCAPIM, Kelly Cristina de Moura; SILVEIRA, Cláudia Alexandra Bolela. Inclusão escolar e jogos cooperativos: uma possibilidade de atuação do psicólogo escolar no processo de socialização e integração. Revista da SPAGESP - Sociedade de Psicoterapias Analíticas Grupais do Estado de São Paulo, São Paulo, vol. 11, n. 2, p. 51-63, jul./dez. 2010. Disponível em: < http://pepsic. bvsalud.org/pdf/rspagesp/v11n2/v11n2a08.pdf >. Acesso em: 1 de junho. 2020.

OLIVEIRA, Vinícius Carlos de; FISCHER, Julianne. Práticas pedagógicas na Educação Física: cooperando e dançando de mãos dadas, buscando a inclusão escolar. Revista Professore, Santa Catarina, v. 4, n. 3, p. 157-176, fev. 2016. Disponível em: < http://periodicos.uniarp.edu.br/professare/article/view/845> Acesso em: 17 de junho. 2020.

SEVERINO, Antônio Joaquim. Metodologia do trabalho científico. 14. ed. rev. ampl. Cortez: São Paulo, 2016.

SILVEIRA, J. da; SERON, B. B. The Inserção de escolares com deficiência nas aulas de Educação Física: percepções dos professores de Educação Física das escolas da Rede Municipal de Florianópolis. Conexões, Campinas, SP, v. 17, p. e019041, 2020. DOl: 10.20396/conex.v17i0.8657908. Disponível em: https://periodicos.sbu.unicamp.br/ojs/index.php/conexoes/article/view/8657908.

Acesso em: 5 ago. 2020.

SIKORA, Giseli. et al. $O$ ensino dos Jogos Cooperativos e a inclusão escolar: contribuições a partir dos pressupostos de Jean Piaget. Revista Eletrônica de Psicologia e Epistemologia Genéticas, Marília,vol. 9, n. 2, pp. 89-111, ago./dez. 2017. Disponível em: <www2.marilia.unesp.br/revistas/index.php/scheme/article/view /7663/4870>. Acesso em: 22 de jun. 2020. 
SOLER, Reinaldo. Educação Física inclusiva na escola: em busca de uma escola plural. Rio de Janeiro: Sprint, 2005.

THIOLLENT, Michel. Metodologia da pesquisa-ação. 18. ed. São Paulo: Cortez, 2011.

Manuscrito recebido em: 06 de novembro de 2020

Aprovado em: 12 de dezembro de 2020

Publicado em: 12 de dezembro de 2020 